\title{
De la palabra hipoteca como significante al goce con el tiempo en El perseguidor: una lectura desde el psicoanálisis*
}

Fecha de recepción: 01 de julio de 2015

Fecha de aprobación: 06 de julio de 2016

\section{Resumen}

La crítica literaria ha señalado que de lo que se trata con Johnny Carter, en El perseguidor, es de la crisis espiritual de un artista; sin embargo, a partir de postulados del Psicoanálisis, como disciplina que se encarga de estudiar lo inconsciente, se puede apreciar que el músico está atravesado por una problemática que implica lo inconsciente y de la que se pueden señalar aspectos específicos para comprender las palabras, actitudes, acciones y reacciones del personaje; se trata de ofrecer una lectura que ilustre ciertos rasgos de la problemática y ayude a esclarecer de lo que se trata con el ser del sujeto-artista. Para conseguir este objetivo, el presente texto lleva a cabo una presentación de la relación significante y cuerpo en la perspectiva psicoanalítica como fundamento de una lectura alternativa del relato literario El perseguidor de Julio Cortázar. El propósito es referir cómo un significante, una palabra, toca el cuerpo del sujeto, lo traspasa y lo pone a gozar. En el caso de El perseguidor, la palabra hipoteca pone a gozar al sujeto con el tiempo. Esto significa referir el tema del goce y de qué sujeto se trata en el caso del músico: un sujeto en una crisis permanente por la incidencia significante.

Palabras clave: inconsciente, goce, significante, tiempo, artista, Cortázar.

Citar: Fonseca Jiménez, H.J. (julio-diciembre de 2016). De la palabra hipoteca como significante al goce con el tiempo en El perseguidor: una lectura desde el psicoanálisis. La Palabra, (29), 117-128. doi: http://dx.doi.org/10.19053/01218530. $\mathrm{n} 29.2016 .5705$

\section{Hernán Joaquín \\ Fonseca Jiménez}

Magíster en Literatura de la Pontificia Universidad Javeriana. Docente de Maestría en Literatura de la Universidad Pedagógica y Tecnológica de Colombia. hernan.fonseca01@ gmail.com

* Artículo de reflexión, producto del proyecto de investigación "Lo real, lo simbólico, lo imaginario" del Grupo de Investigación Senderos del Lenguaje, inscrito en la Dirección de Investigaciones de la UPTC, tema que el autor ya había trabajado con anterioridad y cuyo primer avance fue publicado en la página de la NEL. De este texto se señalan algunos aspectos que iniciaron la indagación, y se desarrollan otros. 


\section{On the Word Mortgage as Signifier of Bliss with respect to Time in El perseguidor [The Pursuer]: a Psychoanalytical Interpretation}

\section{Abstract}

Literary criticism has pointed out that El perseguidor is about the crisis of an artist, Johnny Carter. Nevertheless, based on psychoanalysis, as a discipline in charge of studying the unconscious, it may be appreciated that this musician is traversed by troubles stemming from the unconscious, from which may be derived specific aspects for understanding the words, attitudes, actions and reactions of this character. The aim of this study is to offer an interpretation that illustrates certain features of this problem and helps to clarify the being of the artist-subject. In order to do this, the present text presents the relation between signifier and body from a psychoanalytical perspective, as elements for an alternative reading of The Pursuer by Julio Cortázar. The purpose is to refer to how a signifier, a word, touches the subject's body and runs through it and puts him in a state of bliss or jouissance. In the case of "The pursuer", the word mortgage puts the subject in a state of bliss with respect to time. This implies delving into the matter of bliss [jouissance] and what subject we are referring to, in the case of the musician: a subject in an ongoing crisis due the incidence of the signifier.

Keywords: unconscious, bliss, signifier, time, artist, Cortázar.

\section{Du mot hypothèque comme signifiant au plaisir du temps dans « El perseguidor » [« L'Homme à l'affût »]: une lecture psychanalytique}

\section{Résumé}

La critique littéraire a signalé que Johnny Carter dans L'Homme à l'affût met en évidence la crise spirituelle d'un artiste ; néanmoins, à partir de la psychanalyse : discipline d'étude de l'inconscient, on se demande dans quelle mesure l'analyse de l'inconscient du musicien permet de mieux comprendre les mots, attitudes, actions et réactions du personnage. Il s'agit donc de donner des exemples de cette problématique qui permettent d'expliquer l'être du sujet-artiste. Nous proposons dans cet article une présentation du rapport du signifiant et du corps dans une perspective psychanalytique comme justification d'une lecture alternative de « L'Homme à l'affût » de Julio Cortázar. Nous voulons expliquer de quelle manière le signifiant, la parole, touche le corps du sujet, et le traverse en déclenchant le plaisir. Le sujet de «L'Homme à l'affût » profite du temps avec le mot hypotèque. Nous étudierons donc le plaisir et nous nous demanderons de quel sujet s'agit-il dans le cas du musicien : ce serait un sujet en crise permanente par l'incidence du signifiant.

Mots-clés : inconscient, plaisir, signifiant, temps, artiste, Cortázar. 


\section{Presentación}

La pregunta por la creación literaria y por el creador ha hecho parte de los recorridos que se han llevado a cabo en torno de los estudios literarios. De qué se trata con la actividad creativa y cómo leerla, son interrogantes que han guiado la crítica literaria. La propuesta de lectura de este tema se apoya en la novela corta $\mathrm{El}$ perseguidor de Julio Cortázar, la cual confronta a Johnny Carter, saxofonista, con Bruno, crítico de arte. En este relato, Bruno, el crítico, es el narrador que nos acerca a Johnny, el artista, y sus palabras dan testimonio del desencuentro entre el creador y el crítico. En este sentido, hay unas preguntas orientadoras: ¿de qué se trata la creación artística como efecto de goce en un sujeto afectado por el lenguaje? ¿Cómo pone el lenguaje a gozar a un sujeto, es decir, a satisfacerse pulsionalmente a costa de su propio bienestar? ¿Cómo el tiempo es una de las manifestaciones de goce de este sujeto? Y en cuanto al crítico, ¿qué tan capaz es de comprender y dar cuenta del creador y la creación como respuestas a la relación con el lenguaje?

Estudios como "Entre el artista y el crítico: Basura de Héctor Abad Faciolince", de Leonardo Monroy (2014), realizan una revisión de esta relación artista-crítico de arte. Aquí se reco- noce la proximidad entre la labor del escritor y la del crítico:

En este caso se comprende al crítico como una suerte de escritor (de pastiches) y al escritor que debe conocer el trabajo crítico para realizar su obra con fortaleza. En ambas vías hay una oposición a la inspiración y un juego a favor de la creación literaria como labor disciplinada y razonada, que necesita no solo de la agudeza en la mirada sino, además, de una interpretación de la historia literaria y del trabajo con la palabra y sus múltiples posibilidades (p. 66).

No hay disyunción ni desencuentro, y lo que plantea una novela como Basura es el diálogo entre creación y crítica literaria, como la puesta a prueba de un sujeto como escritor en el contexto de la modernidad, y cuya única promesa es el fracaso; un fracaso que no se problematiza en la perspectiva de una relación problemática del sujeto con el lenguaje.

En El perseguidor, Johnny no fracasa como saxofonista ni como compositor; sin embargo, no puede explicar de qué se trata con su actividad creadora; y Bruno intenta comprender algo de ello que se le escapa a cada instante. La crisis de Johnny tiene que ver con un significante que cayó en una parte de su cuerpo y lo puso a gozar. El presente estudio, cuya fuente es el psicoanálisis lacaniano, ayuda a comprender la creación artística como un resto del goce que se produce en el sujeto por obra de un significante que lo afecta.

En otro estudio, Adela Avila (2014) propone un acercamiento a la comprensión de la creación artística y del creador desde la instancia del cuerpo en su artículo titulado "La germinación de lo siniestro: la belleza en espejo roto". De acuerdo con Ávila, hay un cuerpo habitado por el lenguaje, cuyos efectos movilizan a un sujeto, el artista, a crear. No hay creación sin cuerpo de por medio. Y lo ilustra a través de la lectura de la novela La pianista de E. Jelinek. Su búsqueda de la comprensión de la escritura inicia en interrogar el sujeto mismo y su postura creadora: "Socavar dentro de la propia historia para ir concibiendo otro rostro de la belleza; uno distinto al de la armonía y la mimesis, concebida como perfección. Uno mas bien parecido al que históricamente nos han obligado a ocultar bajo el silencio de un lenguaje refinado, perfumes costosos, ropas suntuosas y maquillaje por toneladas. El rostro de lo excluido, lo transgresor, lo impuro, lo sucio, lo abominable, el tabú que tanto castiga y repugna, pero que en la misma medida, atrae, excita y sublima" (p. 102). La escritura es una respuesta a una incidencia opresiva de la cultu- 
ra, un ámbito en el que el sujeto se rehace y se redescubre: "Una mujer que escribe es una mujer que erige y hace resonar el peso de su voz encarnada, capaz de nombrarse sin miramientos $o$ vergüenzas impostadas por requerimientos sociales de doble moral" (p. 104). Es conciencia de un encuentro doloroso con lo que se ha perdido, con aquello que el otro le quitó al sujeto, en este caso, la mujer. Encuentro con la falta que empuja a un rehacer permanente: "La escritura como retorno, re-encuentro o hallazgo de esa parte que le extraviaron a la mujer a lo largo de la historia, el derecho a ser oída y validada dentro de una sociedad, de la cual ella siempre ha sido una columna vertebral, pero que al mismo tiempo la ha confinado a la invisibilidad, a la negación de su talento y fuerza, bajo el estigma de impureza y culpa" (p. 105).

Otra lectura de esta relación del sujeto con el lenguaje en el contexto de lo cultural, la hace Hernán Javier Pinzón (2014), en "La literatura como in-corporación: el cuerpo como proceso" quien escudriña la relación entre cuerpo y lenguaje de la siguiente manera:

[...] la interconexión cuerpo-lenguaje permite comprender que lo expresado se desarrolla desde el mismo vínculo del cuerpo sobre el mundo de la vida, y que constituye el resca- te que busca la fenomenología en la experiencia humana [...] En esta perspectiva, el cuerpo-lenguaje constituye la experiencia humana y al mismo tiempo es transgresión en el uso del lenguaje como herramienta desencarnada. (p. 94).

Esta relación la desarrolla en diálogo con teorías fenomenológicas, a partir de las cuales intenta nombrar la relación problemática del sujeto con el lenguaje.

De hecho, todos los anteriores autores no que hacen otra cosa que esto: un intento por elaborar una visión sobre la enigmática manera en que el lenguaje habita al sujeto. Para el caso de este artículo, la dimensión simbólica de la relación Johnny/ Bruno (artista/crítico) ofrece una posibilidad de sostener un diálogo con estas búsquedas, a la luz de algunos conceptos psicoanalíticos desde los que se intenta comprender la literatura.

El perseguidor, Johnny, pierde el saxo en el tren, y este es un impase que le ocurre con frecuencia. Esta situación altera a sus amigos, pues extraviar el saxo tiene como consecuencia para ellos la pérdida de una oportunidad de trabajo, e incide en Johnny como una ruptura en su proceso de creación musical y en una parálisis generalizada de sus actividades. La vida y obra de Johnny están interferidas por crisis permanentes que interrumpen su proceso creador y desatan crisis en los demás. A Johnny no le preocupa perder el saxo, incluso le parece divertido y sabe que alguno de sus amigos le conseguirá otro:

Tú no haces más que contar el tiempo -me ha contestado de mal humor-. El primero, el dos, el tres, el veintiuno. A todo le pones un número, tú. Y esta es igual. ¿Sabes por qué está furiosa? Porque he perdido el saxo. Tiene razón, después de todo.

- ¿Pero cómo has podido perderlo? -le he preguntado, sabiendo en el mismo momento que era justamente lo que no se le puede preguntar a Johnny.

-En el metro -ha dicho Johnny-. Para mayor seguridad lo había puesto debajo del asiento. Era magnífico viajar sabiendo que lo tenía debajo de las piernas, bien seguro.

-Se dio cuenta cuando estaba subiendo la escalera del hotel -ha dicho Dédée, con la voz un poco ronca-. $\mathrm{Y}$ yo tuve que salir como una loca a avisar a los del metro, a la policía.

Por el silencio siguiente me he dado cuenta de que 
ha sido tiempo perdido. Pero Johnny ha empezado a reírse como hace él, con una risa más atrás de los dientes y de los labios (Cortázar, 1993, p. 7).

Y más adelante Bruno señala:

Nadie se atreve ya a prestarle un instrumento a Johnny, porque lo pierde o acaba con él en seguida. Ha perdido el saxo de Louis Rolling en Bordeaux, ha roto en tres pedazos, pisoteándolo y golpeándolo, el saxo que Dédée había comprado cuando lo contrataron para una gira por Inglaterra. Nadie sabe ya cuántos instrumentos lleva perdidos, empeñados o rotos. Y en todos ellos tocaba como yo creo que solamente un dios puede tocar un saxo alto, suponiendo que hayan renunciado a las liras y las flautas (Cortázar, 1993, pp. 7-8).

El relato "El perseguidor" es una oportunidad para comprender el más allá del creador, aquello que en ciertos ámbitos se denomina los demonios del artista, que exorciza a través de su creación. En el texto titulado "Significante y goce en 'El perseguidor', el relato de Julio Cortázar" ${ }^{\prime \prime}$ se realizó un acercamiento interpretativo a la pro- blemática de Johnny Carter el músico, a partir de dos conceptos tomados del psicoanálisis: significante y goce, que Lacan desarrolla en el Seminario 20 titulado "Aun", y que incluye la perspectiva del significante como necio: "El asunto es que el discurso analítico introduce un adjetivo sustantivado, la necedad, en cuanto que ella es una dimensión en ejercicio del significante" (Lacan, 2011, p. 30). Además, el significante como Uno: “¡Hay Uno!” (p. 32). Respecto del goce, se quiso señalar que la causa del goce, entendido goce como padecimiento, como satisfacción de la pulsión, a costa del sujeto mismo, viene del significante: "El significante es la causa del goce. Sin el significante ¿cómo siquiera abordar esa parte del cuerpo? ¿cómo sin el significante centrar ese algo que es la causa material del goce? Por desdibujado, por confuso que sea, una parte del cuerpo es significada en este aporte" (p. 33). Y que el significante como instancia del lenguaje es el que gobierna al sujeto, el sujeto está a merced de él: "El significante manda. El significante es ante todo imperativo" ( $p$. 43). A partir del planteamiento de que no hay significado, que lo que hay es efectos del significante a nivel del significado, se intentó ilustrar la problemática del músico: "El significado no es lo que se escucha. Lo que se escucha es el significante. El significado es el efecto del significante" (p. 45).

El significante central, el Uno, que ha incidido en Johnny y le causa efectos de goce, es el significante hipoteca. Un significante de goce que no es el Uno final, sino un significante que da cuenta de un goce, y que, de acuerdo con el testimonio de Johnny, tocó su ser en los inicios de su adolescencia: "¿Tú sabes lo que es una hipoteca? Debe ser algo terrible, porque la vieja se tiraba de los pelos cada vez que el viejo hablaba de la hipoteca, y acababan a los golpes. Yo tenía trece años... pero ya has oído todo eso" (Cortázar, 1993, p. 13). El efecto de goce central y fundamental que produce este significante es sacarlo del tiempo, una vivencia permanente que lo atormenta, lo invade de perplejidad, pues no sabe de qué se trata con el tiempo. La salida a este desencuentro la halla en la interpretación del saxo. El saxo, dice, lo mete en el tiempo. Interpretar el saxofón le ayuda a pacificar la agitación consigo mismo, sosiego momentáneo que se traduce, sin que sea su propósito, en experiencia estética, en creación musical. Se plantea que Johnny tiene como objeto de goce el tiempo, que en el presente texto se retomará y se desarrollará, al

Texto publicado en la página de la NEL Bogotá, nelbogota.blogspot.com segundo semestre de 2015. 
decir de Miller, como una erótica del tiempo.

El sujeto y el lenguaje: una relación problemática con el tiempo

El encuentro con el saxo, con la música que a través de este instrumento musical puede crear Johnny, es también una experiencia singular con el tiempo, un encuentro distinto al que vivía en su casa cuando lo atormentaban las peleas de sus padres a causa de una hipoteca. $\mathrm{Su}$ problemática está articulada a la manera como vive el tiempo; se trata para él de un encuentro imposible, de andar por un laberinto sin encontrar la salida. Algo le falta. Y la falta desencadena una falla. Algo en su estructura de lenguaje no funciona, y esta avería desencadena impasses como el de perder el saxo permanentemente, o elucubraciones sobre el tiempo que aparentemente no conducen a nada. Johnny intenta decir algo sobre la manera como es gozado por el tiempo.

$\mathrm{Su}$ relación con el tiempo tiene diferentes caras. Primero experimenta que el tiempo no pasa: "Me di cuenta cuando era muy chico, casi en seguida de aprender al tocar el saxo. En mi casa había siempre un lío de todos los diablos, y no se hablaba más que de deudas, de hipotecas. ¿Tú sabes lo que es una hipoteca? Debe ser algo terrible porque la vieja se tiraba de los pelos cada vez que el viejo hablaba de la hipoteca y acababan a los golpes" (Cortázar, 1993, p. 13); también experimenta que: "En casa el tiempo no acababa nunca" (p. 14); o cree que: "La música me metía en el tiempo" (p. 14); y advierte algo nuevo: "Cuando empecé a tocar de chico me di cuenta de que el tiempo cambiaba" (p. 15); y, además, reconoce que la religión y la hipoteca: "Existían cuando terminaba de tocar" (p. 16). La relación que guarda con el tiempo es problemática, no pasa o no acaba nunca, algo falla en relación con su manera de vivir el tiempo, y esta falla le arruina su manera de estar en el mundo, de conducirse en él:

$\mathrm{Y}$ justamente en ese momento, cuando Johnny estaba como perdido en su alegría, de golpe dejó de tocar y soltándole un puñetazo a no sé quién dijo: 'Esto lo estoy tocando mañana', y los muchachos se quedaron cortados, apenas dos o tres siguiendo unos compases, como un tren que tarda en frenar, y Johnny se golpeaba la frente y repetía: 'Esto ya lo toqué mañana, es horrible, Miles, esto ya lo toqué mañana', y no lo podían hacer salir de eso, y a partir de entonces todo anduvo mal, Johnny tocando sin ganas y deseando irse (a drogarse otra vez, dijo el técnico de sonido muerto de rabia). (Cortázar, 1993, p. 10).

La intranquilidad de estar repitiendo algo ya hecho, algo ya dicho, de volver sobre lo ya dado y de sentir que la cadena del tiempo, la cronología de ayer, hoy y mañana se le trastoca y lo altera al punto de destruir lo que está haciendo para dar fin a esa vivencia desconcertante con el tiempo.

Se pone de frente al tiempo, al igual que en aquellos momentos en que aparecía el tema de la hipoteca entre sus padres. La hipoteca marca un tiempo: quince o veinte años a futuro que cuando se cumplan, es decir, se pague la deuda, le darán sentido al presente, a ese estar pagando mes a mes una cuota. Un futuro que marca el recorrido y traza un ritmo, una periodicidad: "Esto lo estoy tocado mañana", proviene del "Esto lo estoy pagando en quince años".

La interpretación del saxo lo mete en el tiempo:

Cuando el maestro me consiguió un saxo que te hubieras muerto de risa si lo ves, entonces creo que me di cuenta en seguida. La música me sacaba del tiempo, aunque no es más que una manera de decirlo. Si quieres saber lo que realmente siento, yo creo que la música me metía en 
el tiempo (Cortázar, 1993, p. 14).

Es la manera como interpreta la experiencia del saxo y su relación con la nota musical, como efecto de inclusión, pero que no es otra cosa que hallar en la nota musical y el ritmo una forma de regular el goce que lo acecha. El tiempo de la música ayuda a atemperar su goce. El tiempo, además, no acaba nunca, como repetición incesante en su cabeza, es el tiempo interminable de las peleas interminables de sus padres: "Por eso el tiempo no acababa nunca, sabes. De pelea en pelea, casi sin comer" (Cortázar, 1993, p. 14). Un tiempo incesante como la memoria afectiva que tiene de sus padres, que no se borra ni cambia. Con la nota musical algo cambia y es que ni la religión ni la hipoteca existen. La memoria mortificante se suspende, deja de existir por unos instantes.

Johnny va por la vida traspasado por el tiempo, con un afán de comprenderlo, un empuje permanente a decir algo sobre ese esfuerzo que realiza para decir sobre su vivencia inefable, pues la experiencia de goce es inefable. Es como un objeto que ha sido separado de su cuerpo, objeto que va y vuelve, que pierde $\mathrm{y}$ reencuentra, objeto que fue separado por lo simbólico, un símbolo, la hipoteca, que muerde y divide al sujeto, lo agita, lo causa, lo divide.
Los planteamientos de Jacques Alain Miller en su texto La erótica del tiempo favorecen un acercamiento a la problemática de Johnny. Respecto del tiempo, dice Miller (2001):

Consideremos ahora un poco más de cerca la teoría del tiempo. La dificultad que siempre existe en crearla e incluso el impasse que implica empezar su reflexión, en la medida en que el tiempo es, como tal, una objeción al ser. El pasado no es un ser; lo que ya pasó no es un ser porque es un "no ser más". Tampoco el futuro es un ser porque es un "no ser aún". El pasado y el futuro, por lo tanto, son dos nadas. Es el presente el que aparece como refugio del ser, pero, ¿cuánto tiempo dura el presente? El problema es que el presente no dura (p. 46).

La relación de Johnny con el presente le causa desazón:

En el pan es de día -murmura Johnny tapándose la cara- Y yo me atrevo a tocarlo, a cortarlo en dos, a metérmelo en la boca. No pasa nada, ya sé; eso es lo terrible. ¿Te das cuenta de que es terrible que no pase nada? Cortas el pan, le clavas el cuchillo y todo sigue como antes. Yo no comprendo, Bruno (Cortázar, 1993, p. 53).

¿Qué espera Johnny del tiempo? ¿Qué le resuelva la pregunta por el ser? El tiempo, el presente, no dura y eso lo altera. El ser como posibilidad se desvanece. El tiempo lo desvanece. El ser es el objeto con el que se goza, y Johnny es un sujeto del inconsciente, un sujeto dividido. Vive en un movimiento pendular entre el tiempo como objeto de goce que le da ser, a pesar de que sea a costa de su propio bienestar, y él como sujeto del inconsciente, que se constituye en su lugar de enunciación, esto es, desde donde habla, ve, vive. Lo inconsciente es una paradoja y esta paradoja desespera a Johnny. Lo inconsciente es la falta, el sujeto en falta, y la imposibilidad de un sujeto continuo y coherente. El desencuentro consigo mismo desespera a Johnny. Hay una instancia en él, disimétrica, que le impide estar cómodo en lo de él mismo.

Aparecer y desaparecer son significantes que explican la relación de Johnny con el tiempo, su desespero por no poder sostener el tiempo como la fuente que le da ser. Se trata de una experiencia que circula por su cuerpo, pero se le escapa, se desvanece. Él presencia la actividad inconsciente como aquello que lo desborda, lo rebasa, como lo dice Lacan (1987). Johnny no tiene ser, el tiempo es lo úni- 
co que tiene, con lo único que cuenta para movilizar su ser. Un ser que respecto del tiempo es nada. De la nada y el tiempo, "Hegel leyó en Aristóteles la demostración de la negatividad intrínseca al tiempo. El ahora aristotélico es el lugar donde el ser bascula continuamente en la nada, para luego renacer. Es ahí donde se presenta la esencia del tiempo como operador de una negatividad que nadifica todo lo que es" (Miller, 2001, p. 47).

Este planteamiento puede ayudar a comprender la perspectiva de Johnny y su padecimiento con el tiempo, pues para él significa morir y nacer permanentemente, estar en la vida y comprenderla y estar en la nada. Volverse nada, cuando él quiere comprender, busca un soporte que lo sostenga y lo guíe en ese torbellino que, para él, es el tiempo. El encuentro con lo que le falta le resulta insoportable y la música del saxo le alivia su crisis.

El padecimiento de Johnny con el tiempo, su goce, como encuentro de satisfacción pulsional a costa de él mismo, da cuenta de un sujeto dividido y esta división es la que lo hace decir "esto lo estoy tocando mañana", "esto ya lo toqué mañana" (Cortázar, 1993, p. 10). $\mathrm{Su}$ vivencia con el tiempo y su palabra encarnan la paradoja subjetiva:
Para simplificar, diría: entre el significante pasado y el significante futuro, entre el de antes y el de después. El sujeto tachado [\$] de Lacan recoge todas las paradojas del ahora aristotélico. No hay mejor manera de escribir la negatividad subjetiva que \$. Precisamente cuando calificamos al sujeto como un ser evasivo, fugaz, evanescente, es en efecto un estatuto esencialmente temporal del sujeto (Miller, 2001, pp. 47-48).

Y Johnny vuelca su subjetividad en los diálogos con Bruno y en la música, una subjetividad que es testimonio de un sujeto dividido, en falta:

Cuando Lacan sitúa al objeto $a$ en una figura topológica del cross-cap, el $\$$ es la simple torsión espacial de la cinta de Moebius que se puede reducir a un corte en una superficie. Sitúa el objeto $a$ en un trozo de una esfera; es el factor que desregula el desarrollo uniforme del tiempo. El \& no desregula el tiempo sino el pensamiento cuando se intenta ordenar el tiempo, pero $\$$ es un efecto del significante absolutamente dócil a las cadenas sucesivas de significantes. En cambio el objeto $a$ es un producto, un resto, y como tal, encarna la inercia del goce. A él le podemos atribuir los fenómenos de desaceleración del tiempo y, correlativamente, la inversión de esos fenómenos en aceleración (Miller, 2001, pp. 51-52).

Las crisis de Johnny, en relación con el tiempo, tienen que ver con la imposibilidad como sujeto dividido de regular su goce con el tiempo. Su pensamiento no le responde a la hora de intentar decir sobre su tiempo subjetivo. Hay un objeto, un algo, que se atraviesa y lo descoloca, y su división le genera caos interior. ¿De qué objeto se trata? Del significante hipoteca que perturbó la armonía entre él y el tiempo, pues en su casa el tiempo no pasaba cuando aparecía en los labios de sus padres la palabra hipoteca. Este significante separó algo de su cuerpo, un "algo" que circula en él sin brújula, atendiendo a la inercia del goce, de una satisfacción que es dolor y placer, y que sacrifica a Johnny:

El $\$$ es el sujeto identificado con la flecha del tiempo, aquel que sostiene todas las paradojas del "ahora"; pero \$ no es sin el objeto $a$, que trae consigo todos los pathos del alma: las emociones, los afectos, las pasiones que mantienen la fluctuación anímica, como decía San Agustín. La fluctuación de los estados del alma, con 
su duración, con sus substituciones, con el margen que ellos dejan al sujeto para hacerlos durar o para intentar absorberlos (Mi1ler, 2001, p. 52).

Johnny se propone establecer y mantener un encuentro con el tiempo, que es a la vez exploración de sí mismo y búsqueda de la realidad, como efectos de la regulación del goce: "Pero entonces, dueño de una música que no facilita los orgasmos ni las nostalgias, de una música que me gustaría poder llamar metafísica, Johnny parece contar con ella para explorarse, para morder en la realidad que se le escapa todos los días" (Cortázar, 1993, p. 41), y más adelante señala el mismo Bruno: "Y cuando Johnny se pierde como esta noche en la creación continua de su música, sé muy bien que no está escapando de nada. Ir a un encuentro no puede ser nunca escapar, aunque releguemos cada vez el lugar de la cita" (Cortázar, 1993, pp. 41-42). Intenta retornar el objeto separado de su cuerpo. Lo único que encuentra para satisfacer esta ansia es la música, el saxo. La pulsión y su objeto se depositan en él. Reposan y se pacifican en el momento en el cual Johnny crea una música espléndida. Sabe que no se trata de una elaboración artística ni intelectual, sino de meterse en el tiempo, de poner el objeto en el tiempo musical, en la música, en el saxo, y que eso está más allá de lo que su cerebro puede hacer.

El encuentro con el saxo es lo que Miller (2001) denomina erótica del tiempo: "Una erótica del tiempo nos conduciría sobre todo a hablar de la música como arte del tiempo. La música no eclipsa el tiempo como la pintura; mas bien depura el tiempo, lo maniobra. Sustituye el tiempo imprevisto del objeto a por un tiempo regulado, ordenado, manipulado, con ritmo" (pp. 52-53).

La música como ritmo y secuencia de notas musicales ofrece una medida, un límite, una gramática que ayuda al sujeto a regular su goce con el tiempo. La nota musical como significante es una medida que favorece la regulación del goce. Erótica del tiempo es goce pulsional con el tiempo y posibilidad de maniobrar y depurar ese goce gracias al significante nota musical como instancia de lo simbólico.

Simplemente ocurre, y le satisface o no. Meterse en el tiempo es poner una regulación y elaborar una significación del tiempo, que el tiempo tenga algún significado para él; pero el tiempo es ingobernable, incomprensible, lo desespera. Por momentos, el ejercicio de creación musical como inmersión en el tiempo regula la instancia subjetiva, y Johnny parece estar en armonía con el mundo, con él mismo. Se trata de una vivencia en la que aquello que lo descontrola se ha pacificado y ha encontrado un lugar. Los efectos de esta vivencia deslumbran la sensibilidad musical de Bruno y de quienes rodean a Johnny.

Johnny vuelca su subjetividad en los diálogos con Bruno y en la música, una subjetividad que es testimonio de un sujeto dividido por el lenguaje, vivencia encarnada en la palabra hipote$c a$.

De Bruno a Johnny: la pregunta por el creador y la creación

Bruno es el crítico de arte que como testigo está pendiente del artista por dos razones: porque ha escrito una biografía sobre él que se vende mucho y le preocupe que Johnny con sus comentarios arruine la venta de su libro; Johnny ha leído al menos unas páginas y dialoga con Bruno al respecto:

-Sí, está todo, pero en realidad es como en un espejo -se emperra Johnny.

-¿Qué más quieres? Los espejos son fieles.

-Faltan cosas, Bruno -dice Johnny-. Tú estás mucho más enterado que yo, pero me parece que faltan cosas. 
-Las que te habrás olvidado de decirme -contestó bastante picado. Este mono salvaje es capaz de... (Habrá que hablar con Delaunay, sería lamentable que una declaración imprudente malograra un sano esfuerzo crítico que...Por ejemplo el vestido rojo de Lan -está diciendo Johnny -y es lo único que vale en ese disco. Sí, escuchar atentamente y proceder con rapidez, porque en manos de otras gentes estos posibles desmentidos podrían tener consecuencias lamentables (Cortázar, 1993, p. 75).

Johnny desmiente las apreciaciones e interpretaciones de la actividad artística de Johnny. Se busca, pero no se reconoce en ese espejo que es el libro que ha escrito Bruno. Una biografía que, como crítico de arte que es Bruno, se fundamenta en consideraciones estéticas sobre la música que compone Johnny, a quien le resultan, sino extrañas, al menos incomprensibles, pues la intención primaria de Johnny no es estética, es de otra índole, y pone en riesgo la biografía: "Mientras no pase de las alucinaciones, lo peor sería que desmintiera las ideas del fondo, el sistema estético que tantos elogios [...]" (Cortázar, 1993, p. 75).

La otra razón que empuja a Bruno a acercarse al músico obede- ce a su interés por comprender, por saber, quién es Johnny y de qué se trata con él como creador de una música formidable. De entrada, Bruno manifiesta la imposibilidad de acceder a una comprensión del fenómeno creativo llamado Johnny: "Pienso melancólicamente que él está al principio de su saxo mientras yo vivo obligado a conformarme con el final. Él es la boca y yo la oreja, por no decir que él es la boca y yo... Todo crítico, ay, es el triste final de algo que empezó como sabor, como delicia de morder y mascar" (Cortázar, 1993, p. 15). Es un enigma insondable y él solamente sabe que del lado del saxo está Johnny el artista y del lado de quien escucha está él sin saber cómo es posible que un sujeto como Johnny, drogadicto y casi primitivo, pueda componer música valiosa: "Creo que lo admiro todavía más por eso, porque es realmente el chimpancé que quiere aprender a leer, un pobre tipo que se da con la cara contra las paredes, y no se convence y vuelve a empezar" (Cortázar, 1993, p. 63).

Bruno presta su oído para escuchar la angustia y el desasosiego de Johnny, como expresión de su impotencia. Johnny elucubra, y hasta reconoce en sus elucubraciones cierta lucidez. Pero Bruno no comprende, solamente da testimonio de lo que vive y padece el músico, sin que dé cuenta de ello en su libro. En este libro ofrece un semblante de Johnny como músico genial, pero no refiere ni sus crisis ni su locura, de las que no comprende nada. Incomprensión que refiere en varios momentos:

Yo que me he pasado la vida admirando a los genios, a los Picasso, a los Einstein, a toda la santa lista que cualquiera puede fabricar en un minuto ( $\mathrm{y}$ Gandhi, y Chaplin, y Stravinsky), estoy dispuesto como cualquiera a admitir que esos fenómenos andan por las nubes, y que con ellos no hay que extrañarse de nada. Son diferentes, no hay vuelta que darle. En cambio la diferencia de Johnny es secreta, irritante por lo misteriosa, porque no tiene ninguna explicación" (Cortázar, 1993, p. 54).

Lo pone como una cuestión de diferencia, de un sujeto que se sale de la regla, el sujeto que es la excepción a la regla, que es finalmente el efecto que produce el lenguaje en el sujeto, como lo señala Bustamante: "Si todos entran de la misma manera al lenguaje y dejan excluido el mismo elemento, no tendríamos la presencia de lo singular, sino de lo universal." (Seminario "Lo simbólico a partir de Lacan", Maestría en Literatura, 2010).

¿Por qué tanta impotencia para comprender a Johnny y hablar 
con él, y referir los vuelcos de su alma y atar a su admiración por su música la problemática de Johnny? Bruno es un crítico de arte que lee a Johnny como artista, como genio creador, no como un sujeto de lenguaje que padece el lenguaje. Es una lectura que a Bruno no le interesa. Lo que nos enseña "El perseguidor" es que la creación va más allá de la música misma y desborda categorías estéticas, historias del arte, tradiciones artísticas. La explicación de qué es Johnny como creador trasciende la idea de creador como trabajador del lenguaje, en este caso el lenguaje del jazz, y apunta, como lo señala Bustamante, a dar cuenta de un real que agobia al sujeto, de un padecimiento:

Nadie puede saber qué es lo que persigue Johnny, pero es así, está ahí, en Amorous, en la marihuana, en sus absurdos discursos sobre tanta cosa, en las recaídas, en el librito de Dylan Thomas, en todo lo pobre diablo que es Johnny y que lo agranda y lo convierte en un absurdo viviente, en un cazador sin brazos y sin piernas, en una liebre que corre tras de un tigre que duerme (Cortázar, 1993, p. 58).

Guillermo Bustamante lo expresa de la siguiente manera cuando refiere de lo que se trata con el trabajo creador, ya sea de escritores, pintores o músicos, y lo que está implicado y comprometido en su quehacer más allá de intenciones estéticas:

Mas bien lo que lo hace trabajar, es algo ligado a su propio padecimiento, que tiene que ver con la pulsión; es a lo que llamamos "real" y, por supuesto, tiene que ver con lo inconsciente, pero también con lo que no se deja tramitar por el aparato psíquico.

No hay "verdaderos" escritores. Hay caminos de satisfacción de la pulsión. Uno puede ser el de la escritura... pero ése no se explica como algo que el sujeto decide simplemente por "voluntad". ¿No hay acaso testimonios en los grandes escritores de "empujes" a la escritura, más allá de sus propósitos? De otro lado, como dice Borges (no cito textualmente): mientras los otros se deleitan con mis versos, yo los he parido con sangre (Conversación personal, 2010).

El artista es un sujeto que ha escogido cierto lenguaje para trabajar y purgar un enigma que lo atormenta. No se trata de un intelectual que se ha hecho a un saber sobre la historia del arte y los requerimientos técnicos y preceptivos de la creación, ni está construyendo un saber al respecto; mucho menos puede explicar, al menos estéticamente, de qué se trata con su creación, sus motivaciones originarias, que para él son todo un misterio y fuente de mortificación, y tampoco da cuenta de las claves de su arte. Esta serie de rasgos constitutivos del alma de una artista mantienen en la perplejidad a Bruno y la expresa de la siguiente manera:

Es lo de siempre, de pronto me alegra poder pensar que los críticos son mucho más necesarios de lo que yo mismo estoy dispuesto a reconocer (en privado, en esto que escribo) porque los creadores, desde el inventor de la música hasta Johnny pasando por toda la condenada serie, son incapaces de extraer las consecuencias dialécticas de su obra, postular los fundamentos y la trascendencia de lo que están escribiendo o improvisando (Cortázar, 1993, p. 76).

El artista es un sujeto que lleva como telón de fondo de su labor un entramado de lenguaje que lo pone en condición de buscar o perseguir el significante o significantes que lo explican, lo justifican y le dan soporte a su existencia. 


\section{Referencias}

Ávila Rodríguez, A. (enero-junio de 2014). De la germinación de lo siniestro: La belleza en espejo roto. La palabra, (24), 99-101. doi: http://dx.doi.org/10.19053/01218530.2505

Cortázar, J. (1993). El perseguidor. Madrid: Alianza Editores S. A.

Lacan, J. (2011). Seminario 20. Madrid: Paidós.

Lacan, J. (1987). Seminario 11. Madrid: Paidós.

Miller, J. (2001). La erótica del tiempo. Buenos Aires: Editorial Tres Haches.

Monroy Zuluaga, L. (julio-diciembre de 2014). Entre el artista y el crítico: Basura de Héctor Abad Faciolince. La palabra, (25), 57-68. doi: http://dx.doi.org/10.19053/01218530.2870

Pinzón, H.J. (enero-junio de 2014). La literatura como in-corporación: el cuerpo como proceso. La palabra, (24), 91-97. doi: http://dx.doi.org/10.19053/01218530.2504

Velásquez, C. (2010). Un rasgo, fundamento de las identificaciones. En H. Gallo (2011). Clínica y teoría de las identificaciones. Bogotá: Nueva escuela lacaniana de Medellín.

Velásquez, J. (2010). Las identificaciones y el inconsciente Real. En H. Gallo (2011). Clínica y teoría de las identificaciones. Bogotá: Nueva escuela lacaniana de Medellín. 